\title{
VARIEDADE DE CAPITALISMO NO BRASIL: O PROGRAMA MINHA CASA MINHA VIDA E AS RESPOSTAS À DESIGUALDADE SOCIAL NO CONTEXTO DA CRISE ECONÔMICA DE $2008^{1}$
}

\author{
Nayara Macedo ${ }^{2}$ \\ Noëlle Silva ${ }^{3}$
}

\section{Resumo:}

A desigualdade social, embora passe por um processo de diminuição, continua sendo um problema no Brasil, país marcado por grande discrepância de renda. O presente artigo se propõe a estudar tal temática, por meio de uma pesquisa bibliográfica e documental do Programa Minha Casa Minha Vida - PMCMV. O objetivo é analisar as respostas que o Programa tem dado no contexto da crise sob a ótica da abordagem "variedades de capitalismo". As conclusões giram em torno de um sistema misto, que compreende tanto a ação do Estado como propulsor da inclusão social como sua faceta hierárquica e centralizadora.

Palavras-chave: políticas públicas, desigualdade, variedades de capitalismo.

\section{Resumen:}

Aunque haya pasado por un proceso de disminución, la desigualdade social sigue siendo un problema en Brasil, país en donde ha existido una gran desigualdad de ingreso. En el presente estudio, se propone examinar este tema por medio de una investigación bibliográfica y documental del Programa Minha Casa Minha Vida (PMCMV). Bajo la perspectiva de "variedades de capitalismo", el objetivo es analizar las respuestas que el Programa ha formulado en una coyuntura de crisis económica. Las conclusiones se refieren a la existencia de un sistema mixto, que comprende tanto la acción del Estado como propulsor de la inclusión social, como la acción de este ente desde una faz jerárquica y centralizadora.

Palabras-clave: políticas públicas, desigualdad, variedades de capitalismo

\begin{abstract}
:
Although efforts have been made to reduce social inequality, it is still a major issue in Brazil, a country marked by great income inequality. The proposal of this article is to study the problem of inequality through a bibliographical and documental research of the Brazilian governmental program "Minha Casa Minha Vida". The main goal is to analyze the responses given by the program in the context of the economic crisis. For this purpose, we tackle the issue through the approach "varieties of capitalism". The conclusions indicate a mixed system composed by State actions for social inclusion and a high level of hierarchy.
\end{abstract}

Keywords: public policies, inequality, varieties of capitalism.

\footnotetext{
${ }^{1}$ Este artigo trata de um estudo preliminar do PMCMV no contexto da Crise de 2008. Devido a algumas limitações, não foi possível avançar no estudo, bem como mapear todos os atores chaves. Pretendemos sanar essas lacunas futuramente, na continuidade do estudo. Agradecemos ao Professor Dr. Paulo Calmon pelas valiosas sugestões dadas ao desenvolvimento deste artigo. Ressaltamos, contudo, que possíveis erros e equívocos cabem apenas às autoras.

2 Mestranda em Ciência Política da Universidade de Brasília - UnB. Agradece ao Conselho Nacional de Desenvolvimento Científico e Tecnológico - CNPq do qual é bolsista.

3 Mestranda em Ciência Política da Universidade de Brasília - UnB. Agradece a Coordenação de Aperfeiçoamento de Pessoal de Nível Superior - CAPES da qual é bolsista.
} 


\section{INTRODUÇÃO}

O problema da desigualdade social tem permeado o contexto brasileiro desde o começo da sua história até os dias atuais. Embora o país tenha adquirido avanços nessa área, os dados acerca da distribuição ainda são alarmantes. Apenas para citar um exemplo: “em 2001, enquanto os 50\% mais pobres se apropriavam de apenas 14,3\% da renda nacional, o 1\% mais rico apropria-se de 13,3\% do total de rendimentos" (FLEURY, 2006, p.11).

Com a crise econômica, que se iniciou em 2008, a desigualdade ganha nova proeminência no cenário mundial. Nos últimos anos, o governo federal tem empreendido esforços para mitigar esse problema, principalmente por meio de programas de transferência de renda e de acesso às condições básicas de sobrevivência. Um dos programas governamentais voltados à redução da desigualdade é o Programa Minha Casa Minha Vida, cujo objetivo central é a construção de moradias populares.

O presente trabalho tem como finalidade propor uma análise da forma com a qual o Brasil tem respondido aos desafios impostos pela crise econômica relacionados à desigualdade social, tendo em vista seu arcabouço institucional. Para tal, utiliza-se o marco teórico de Variedades de Capitalismo (VoC), o qual considera a economia política e os arranjos institucionais em termos de como os problemas de coordenação são resolvidos.

Nesse sentido, a abordagem de VoC classifica as economias políticas dos países de acordo com as formas com as quais esses países resolvem os problemas de coordenação em diferentes esferas. Aplicando ao caso brasileiro, são expostas duas visões acerca de sua economia: a primeira (trabalhos de Schneider) foca nos aspectos hierárquicos, enquanto a segunda (proveniente da visão de Renato Boschi) destaca o papel do Estado no desenvolvimento social.

Nosso argumento aqui é que o Brasil engloba as duas perspectivas: enquanto há elementos hierárquicos em sua configuração na relação entre o setor privado e o público, o Estado ainda possui uma posição central na busca pelo desenvolvimento. Isso será demonstrado por meio de um estudo de caso sobre o Programa Minha Casa Minha Vida, destacando os elementos hierárquicos e desenvolvimentistas presentes no Programa.

As técnicas de pesquisa utilizadas foram - em sua maioria - as pesquisas bibliográfica e documental. A intenção inicial era realizar entrevistas semiestruturadas com membros do Executivo, porém foi obtida apenas uma resposta dentro da amostra selecionada, a qual, entretanto, foi bastante útil na análise do Programa. Nessa análise, os 
principais elementos são o envolvimento do setor público com o privado e a divisão entre beneficiados (mapeamento de stakeholders) em uma lógica de oferta e demanda.

O artigo encontra-se dividido nas seguintes seções: a) arcabouço teórico, em que são apresentadas as teorias e perspectivas referentes à abordagem de Variedades de Capitalismo, assim como sua aplicação no contexto brasileiro; b) Estudo do caso específico, em que será desenvolvida a análise sobre o Programa em questão e c) As conclusões obtidas com o estudo. Pretende-se, assim, contribuir para o debate teórico com uma discussão inicial e proposta de estudo empírico de forma a enfatizar possibilidades e limitações desse conteúdo no contexto do Brasil.

\section{ARCABOUÇO TEÓRICO}

\subsection{A abordagem "Variedades de Capitalismo" (VoC)}

O campo comparativo da economia política esteve interessado na relação entre diferenças nas economias políticas nacionais e as formas de agregar desempenho econômico. As respostas estiveram associadas aos desafios enfrentados pelas economias dos ditos países desenvolvidos (HALL E GINGERICH, 2009, p.2-4). Foram justamente esses desafios que deram origem a três abordagens no estudo comparativo do capitalismo: a abordagem modernista, o neocorporativismo e a perspectiva dos sistemas sociais de produção. Assim, todas as três abordagens estiveram relacionadas, em larga medida, ao contexto dos países desenvolvidos.

Concebida no período pós-guerra, a abordagem modernista tinha como foco o desafio da modernização das indústrias dos países desenvolvidos, nas quais ainda predominavam práticas pré-guerra. Havia um esforço, de parte dos analistas, em identificar os atores relevantes em termos de construir um plano para a indústria. Os bancos e os oficiais públicos eram vistos como tais atores (HALL E SOSKICE, 2001, p.2).

Uma segunda abordagem foi desenvolvida quando a inflação se tornou o maior problema dos países desenvolvidos. Dessa forma, o neocorporativismo esteve associado à capacidade de negociação do Estado com os empregados e os sindicatos com relação a temas como salários e condições de trabalho. Nessa ótica, a capacidade de barganha de uma nação estaria relacionada à centralização dos sindicatos (HALL E SOSKICE, 2001, p.3).

Por outro lado, os sistemas sociais de produção ganharam mais proeminência nas décadas de 1980 e 1990. Tal perspectiva estava centrada no comportamento das empresas, 
em como elas geravam confiança e aprendizado. $O$ enquadramento teórico trazido pela abordagem intitulada de "Variedades de Capitalismo" (VoC) rompe com essas três abordagens anteriores devido ao foco nas firmas e à perspectiva de que as instituições da economia política influenciam o comportamento (HALL E SOSKICE, 2001, p.3-5).

Nesse contexto, instituições são compreendidas tais como na definição de Douglass North (1991, p.97), que as caracteriza como "constrangimentos que estruturam interações políticas, econômicas e sociais". As instituições, nessa definição, podem ser tanto regras formais quanto restrições informais, como costumes, tradições e códigos de conduta (NORTH, 1991, p.97-98). As instituições, portanto, não se restringem às regras formais.

Nesse contexto, entendimentos compartilhados sobre como os atores devem agir também devem ser levados em consideração (HALL E SOSKICE, 2001, p.13-14). Tal observação assemelha-se com a lógica da adequação (appropriateness), a qual se baseia no pressuposto de que regras organizacionais são relevantes na definição do que seria um bom tomador de decisões (MARCH, 1994, p.57-100). Os arranjos institucionais delimitam a estratégia utilizada segundo a variedade de capitalismo.

Segundo a abordagem VoC, a economia política é vista como um terreno em que múltiplos atores procuram avançar em seus interesses de forma racional e em uma interação estratégica com os outros. Há, portanto, uma ênfase na dimensão relacional da empresa, em termos da relevância de suas relações internas e externas. Tais relações pressupõem problemas de coordenação, em que o sucesso depende da efetividade na coordenação de variados atores (HALL E SOSKICE, 2001, p.6-7). Como afirmam Hall e Gingerich (2009, p.2), essa abordagem faz uma distinção entre as economias capitalistas com base nas "formas com as quais firmas e outros atores coordenam seus esforços".

A partir dessas diferenças, é feita uma divisão entre Economias de Mercado Liberais (EML) e Economias de Mercado Coordenadas (EMC). Essa classificação refere-se às formas com as quais as economias lidam com o problema da coordenação (HALL E SOSKICE, 2001, p.8). Hall e Soskice (2001, p.21-36) focam em cinco esferas nas quais os relacionamentos são desenvolvidos para resolver os problemas de coordenação:

i. Relações industriais: refere-se aos problemas relativos à barganha de salários e condições de trabalho. Abrange, portanto, a relação entre empresas e força de trabalho, as organizações que representam os trabalhadores e os próprios empregados. 
ii. Educação e treinamento vocacional: abrange o problema de garantir à força de trabalho as habilidades necessárias, enquanto os trabalhadores enfrentam o dilema de decidir o quanto investir nessas habilidades.

iii. Governança corporativa: engloba os problemas relacionados à questão do investimento, no sentido da busca das firmas por investimento e da busca dos investidores pelo retorno desse investimento.

iv. Relação entre firmas: abrange a questão da oferta e da demanda e do acesso à tecnologia, em um contexto de relacionamento que empresas desenvolvem entre si.

v. Relação com empregados: refere-se aos problemas de coordenação com os próprios empregados da firma. O cerne do problema aqui é garantir que os empregados cooperem uns com os outros.

Assim, para prosperar, as firmas devem atuar nessas esferas em conjunto com outros atores para:

\begin{abstract}
levantar financiamento (em mercados financeiros), regular salários e condições de trabalho (relações industriais), assegurar que trabalhadores tenham as habilidades necessárias (educação e treinamento), garantir acesso à tecnologia (via relação entre-firmas), competir por consumidores (em mercados de produtos), e assegurar a cooperação de sua força de trabalho (relações firma-trabalhadores) (HALL E GINGERICH, 2009, p.4).
\end{abstract}

O problema central é, portanto, a coordenação, cuja natureza depende do tipo de arranjos institucionais existentes, os quais variam de acordo com a divisão entre EML e EMC (HALL E GINGERICH, 2009, p.4-5). Nas Economias de Mercado Liberais (EML), as principais instituições são a hierarquia e os arranjos competitivos do mercado. Por outro lado, nas Economias de Mercado Coordenadas (EMC), as firmas dependem mais de relacionamentos não mercadológicos. Dessa maneira, as instituições mais relevantes nas EMCs são aquelas que reduzem a incerteza que os atores possuem sobre o comportamento dos demais. Instituições que promovam troca de informações, monitoramento do comportamento e possibilidade de sanções são relevantes para induzir um comportamento cooperativo (HALL E SOSKICE, 2001, p.8-33).

Dessa forma, EMLs e EMCs atuam com estratégias distintas devido às diferenças nos arranjos institucionais das respectivas economias políticas. A presença de complementariedades institucionais reforça essas diferenças (HALL E SOSKICE, 2001, p.17-18). Um conjunto de instituições é considerado como complementar a outro quando a 
sua existência indica retornos no outro (HALL E GINGERICH, 2009, p.3). Em economia política, isso significa que nações com um tipo particular de coordenação tendem, portanto, a desenvolver práticas semelhantes em outras esferas (HALL E SOSKICE, 2001, p.8-33).

Entretanto, isso também pode indicar que "esforços em reformar uma esfera da economia política pode gerar resultados econômicos negativos se não estiver acompanhado por reformas paralelas em outras esferas" (HALL E GINGERICH, 2009, p.3).

As atuações nas esferas segundo a divisão entre EML e EMC exposta por Hall e Soskice (2001) podem ser descritas de acordo com a tabela abaixo:

\begin{tabular}{|c|c|c|}
\hline $\begin{array}{l}\text { Características / } \\
\text { Tipo de } \\
\text { economia }\end{array}$ & $\begin{array}{l}\text { Economia de Mercado Coordenada } \\
\text { (EMC) }\end{array}$ & $\begin{array}{l}\text { Economia de Mercado } \\
\text { Liberal (EML) }\end{array}$ \\
\hline $\begin{array}{c}\text { Sistema } \\
\text { financeiro } \\
\text { (mercado para } \\
\text { governança } \\
\text { corporativa) }\end{array}$ & $\begin{array}{c}\text { Presença de redes densas ligando os } \\
\text { gerentes e os técnicos aos seus pares em } \\
\text { outras firmas. Confiança e reputação } \\
\text { estão disponíveis pelas relações } \\
\text { próximas. }\end{array}$ & $\begin{array}{l}\text { Encoraja firmas a estarem } \\
\text { atentas aos ganhos e preços } \\
\text { do mercado. }\end{array}$ \\
\hline $\begin{array}{l}\text { Estrutura } \\
\text { interna }\end{array}$ & $\begin{array}{l}\text { Fortalece sistema de redes (pouca } \\
\text { capacidade de ação unilateral) }\end{array}$ & - \\
\hline $\begin{array}{l}\text { Relações } \\
\text { industriais }\end{array}$ & $\begin{array}{l}\text { Força de trabalho habilidosa. Salários } \\
\text { são negociados com sindicatos. }\end{array}$ & $\begin{array}{l}\text { Relacionamento ocorre } \\
\text { entre trabalhador individual } \\
\text { e empregadores. Mercado } \\
\text { de trabalho é mais fluido. }\end{array}$ \\
\hline $\begin{array}{l}\text { Sistema de } \\
\text { educação e } \\
\text { treinamento }\end{array}$ & $\begin{array}{l}\text { Exigência de habilidades específicas. Há } \\
\text { maior papel dos sindicatos e associações } \\
\text { representativas dos empregadores. }\end{array}$ & $\begin{array}{l}\text { Educação formal foca em } \\
\text { habilidades gerais. }\end{array}$ \\
\hline $\begin{array}{l}\text { Relações entre } \\
\text { firmas }\end{array}$ & $\begin{array}{l}\text { Relação ocorre de modo a facilitar a } \\
\text { difusão de tecnologias (não pode } \\
\text { depender muito do movimento de } \\
\text { pessoal das áreas de engenharia ou } \\
\text { científica, pois os contratos são } \\
\text { geralmente mais longos). }\end{array}$ & $\begin{array}{l}\text { A existência de contratos } \\
\text { formais e de relações } \\
\text { padrões de mercado atenta } \\
\text { para a fluidez e maior } \\
\text { movimentações de pessoas } \\
\text { entre firmas, o que pode } \\
\text { contribuir para a difusão de } \\
\text { tecnologia por meio dessa } \\
\text { movimentação. }\end{array}$ \\
\hline
\end{tabular}


Cabe destacar aqui, porém, que EMC e EML sequer representam categorias plenamente homogêneas. No caso das EMCs, por exemplo, a coordenação pode ser baseada na indústria ou em grupo, como demonstram as situações distintas da Alemanha, em que se tem maior atuação dos sindicatos e das associações; e do Japão, em que há famílias de empresas de diferentes setores que estão interconectadas. Ademais, o objetivo dessa distinção não é indicar um nível de superioridade entre as economias, uma vez que ambas possuem capacidade de sucesso econômico (HALL E SOSKICE, 2001, p.34-36).

A abordagem VoC implica em uma reconstrução da teoria das vantagens comparativas. Em sua versão original, era demonstrado que o livre comércio não empobrecia as nações, com base no aumento de produtividade causado pela especialização. A mais influente versão focava nos fatores básicos - terra, capital e trabalho - os quais condicionavam a produção. Assim, o país produziria o bem em que os fatores fossem mais abundantes (HALL E SOSKICE, 2001, p.36).

Entretanto, a expansão da troca entre indústrias e a mobilidade do capital vieram a contestar essas teorias. Hall e Soskice (2001, p.36-45) argumentam em prol de uma teoria da vantagem institucional comparativa, em que a estrutural institucional de determinada economia política provê vantagens para empresas em relação a certas atividades. A viabilidade de diferentes modos de coordenação condiciona a eficiência com a qual empresas desempenham certas atividades e, por consequência, a eficiência na produção de alguns tipos de bens e serviços.

Uma dessas vantagens comparativas consideradas seria a inovação, a qual é influenciada pela estrutura institucional. A produção de bens e serviços requer tipos específicos de inovação, os quais estão condicionados ao quadro institucional. Nas EMLs, há mais facilidade para inovações radicais, enquanto as EMCs possuem mais facilidade com inovações incrementais. Assim, enquanto as EMLs são voltadas à inovação radical, as EMCs estão mais propensas a uma inovação de tipo incremental. Dessa maneira, há uma especialização no tipo de inovação que, por sua vez, direciona o tipo de produto (HALL E SOSKICE, 2001, p.38-50).

Já em relação ao processo de políticas públicas (policy-making), o cerne do problema se torna a indução de cooperação entre os agentes, ou seja, é necessário fazer com que os atores cooperem uns com os outros de forma mais eficiente. Nas situações em que os mercados são utilizados para essa finalidade, a tarefa dos responsáveis pela formulação das políticas públicas é aperfeiçoar o funcionamento do mercado. Em um contexto de 
interação estratégica, por outro lado, o desafio é justamente aperfeiçoar os resultados que emergem dessa interação (HALL E SOSKICE, 2001, p.45-51).

No campo das políticas econômicas, as políticas formuladas serão eficientes caso os incentivos gerados forem complementares às capacidades inseridas na economia política existente. A causa disso é a dependência das políticas acerca dos instrumentos disponibilizados pelo Estado de acordo com a economia política. Verifica-se uma complementariedade entre regime político e economia política, uma vez que o caráter do regime contribui para o desenvolvimento de uma espécie particular de economia devido ao condicionamento dos níveis de especificidade dos ativos (HALL E SOSKICE, 2001, p.4551).

No âmbito das políticas sociais, é enfatizado o papel dos grupos de negócios no desenvolvimento do Estado do bem-estar e a importância das políticas sociais para as empresas, em contraposição à perspectiva convencional que enxergava o campo dos negócios como oposto a esse tipo de iniciativa. Uma das consequências da abordagem relacional é a consideração sobre o apoio no relacionamento entre as firmas promovido pelas políticas sociais. Há diversas formas com as quais as políticas sociais podem auxiliar as firmas em suas estratégias relacionais e, por essa razão, tipos de Estado de bem-estar estão também associados a tipos de economias políticas (HALL E SOSKICE, 2001, p.45$51)$.

Nesse sentido, EMLs estariam relacionadas a Estados de bem-estar liberais, cujos baixos incentivos reforçam a fluidez do mercado de trabalho. Já as EMCs tendem a se identificar com Estados de bem-estar que apoiem as estratégias corporativas encontradas nesse tipo de economia (HALL E SOSKICE, 2001, p.45-51).

A consideração de variedades de capitalismo relacionadas a arranjos institucionais específicos podem, portanto, auxiliar a compreensão de diversas temáticas, inclusive mudanças em políticas públicas face aos arranjos da economia política. Entretanto, é importante não deixar de lado as críticas feitas a essa abordagem, a qual - segundo Streeck e Thelen (2005, p.4-33) - não seria suficiente para explicar mudanças na contemporaneidade.

De acordo com Streeck e Thelen (2005, p.4-33), grande parte das análises recentes tem focado na continuidade em detrimento da mudança. A ênfase na estabilidade institucional indicaria um problema geral na análise contemporânea, que se baseia em constrangimento e continuidade. Os autores argumentam que equiparar a mudança maior com interrupção de continuidade tende a reduzir mudanças observáveis ao ajuste com 
propósito de estabilidade. Assim, é feita uma distinção entre processos de mudança, os quais podem ser incrementais ou abruptos, e resultados da mudança, que podem ser direcionados à continuidade ou à descontinuidade.

Ademais, a abordagem VoC surgiu - como foi demonstrado anteriormente - no contexto das economias desenvolvidas. Cabe indagar se tal instrumento analítico é capaz de auxiliar a compreensão de outros tipos de economia, que abrangem realidades distantes do continente europeu ou dos Estados Unidos. Esse assunto será discutido no próximo tópico.

\title{
2.2 Variedades de Capitalismo na América Latina
}

Como demonstrado na seção anterior, o enquadramento teórico na perspectiva "Variedades de Capitalismo" (VoC) esteve relacionado ao contexto das economias taxadas como desenvolvidas. Como afirma Boschi (2011, p.8):

\begin{abstract}
(...) a literatura adotava uma visão extremamente primeiro-mundista (americanista ou eurocêntrica) na caracterização das mudanças institucionais no capitalismo, relegando totalmente os países da periferia em geral e os países chamados de emergentes - adjetivo conotando a possibilidade de alteração de suas respectivas posições relativas no cenário da globalização - mas descartada nas abordagens teóricas.
\end{abstract}

O estudo de diferentes formas de capitalismo na América Latina passou por diversos estágios durante décadas. Durante as décadas de 60 e 70, o foco era na chamada teoria da dependência, em que os problemas da América Latina eram vistos como consequência de sua dependência, de constrangimento interno e da falta de dinamismo interno. Em 1980, a atenção voltou para a intervenção estatal na economia e posteriormente para estratégias de desenvolvimento (SCHNEIDER, 2009, p.3).

Embora essas análises tenham trazido contribuições, ainda restaram algumas lacunas, como a governança corporativa. A grande inovação da abordagem $\mathrm{VoC}$ na América Latina foi, portanto, ter trazido a firma como ator relevante, uma vez que os estudos anteriores estavam mais centrados no Estado (SCHNEIDER, 2009, p.3).

Schneider (2009, p.4-5) traz uma nova categoria para classificar os países latinoamericanos: a Economia de Mercado Hierárquica $(\mathrm{EMH})$, que é caracterizada por grupos de negócios diversificados, corporações multinacionais, relações de trabalhos atomísticas e trabalho de baixas habilidades. Quanto aos grupos de negócios, as companhias na América Latina estão divididas entre grandes grupos domésticos e empresas multinacionais.

O autor ainda salienta quatro aspectos dessas companhias: a diversificação delas em subsidiárias com pouca relação mercadológica, o controle que cada grupo mantém de 
dúzias de firmas, a predominância de um pequeno número de grandes grupos detendo maiores parcelas do Produto Interno Bruto (PIB) e o fato de grande parte dos grupos serem geridos por famílias. Multinacionais também detém uma grande parcela da economia na maior parte dos países latino-americanos (SCHNEIDER, 2009, p.4-7).

As relações de trabalho são chamadas de "atomísticas" porque os trabalhadores possuem uma relação fluida com a firma e a relação entre os próprios trabalhadores tende a não ser horizontal por meio dos sindicatos. Na América Latina, a força de trabalho organizada tende a ser mais politizada e controlada pelo Estado (COOK apud SCHNEIDER, 2009, p.12), o que resulta na baixa probabilidade dos sindicatos servirem na coordenação entre trabalhadores e empregadores (SCHNEIDER, 2009, p.11-13).

Quanto à educação, “os níveis educacionais na América Latina permanecem mais baixos que aqueles encontrados nos países desenvolvidos e na Ásia Leste" (SCHNEIDER, 2009, p.13), além dos governos desses países apresentarem menos investimento em treinamento de trabalhadores desempregados (SCHNEIDER 2009, 13-14).

Essas características cobrem em grande medida aquelas esferas expostas por Hall e Soskice (2001), nas quais a hierarquia substitui ou atenua as relações de mercado ou coordenadas (SCHNEIDER, 2009, p.6).

Hierarquia nesse sentido corresponde à forma como as decisões são tomadas. No exemplo dado por Schneider (2009, p.6-13): enquanto nas EMLs as decisões são tomadas com base no mercado e nas EMCs elas são mais negociadas, nas EMHs, são tomadas unilateralmente por firmas ou associações de negócios. Isso implica em uma menor força por parte dos sindicatos.

Ademais, na dimensão "relações industriais", há uma regulação “de cima para baixo" por parte do governo nacional, com reforço dos tribunais. No que concerne à governança corporativa, a maioria delas é controlada ou gerida por seus donos. Nas relações entre firmas, alguns setores são oligopolistas e outros são controlados pelo Estado, embora haja alguns competitivos (SCHNEIDER, 2009, p.6).

Aqui também permanece o conceito de complementariedade, em que as EMHs apresentam complementaridades negativas que sustentam ou mantém os arranjos institucionais e impedem que as economias latino-americanas se aproximem mais das EMCs e das EMLs (SCHNEIDER, 2009, p.14-21).

Boschi (2011), no entanto, salienta que esse tipo de abordagem negligenciava um fator relevante da política brasileira: o protagonismo do Estado como ator estratégico no 
sentido de operar mudanças, principalmente na criação de condições sociais favoráveis, e seu papel no estímulo ao investimento por meio de políticas industriais. Dessa forma,

\begin{abstract}
Em lugar de um dado eventual no ambiente institucional em que as firmas atuam - como tende a ser a caracterização do papel do Estado na literatura centrada nos casos dos países avançados, no caso dos países emergentes e da América Latina em geral - tal aspecto seria crucial, principalmente no que tange à adoção de políticas sociais de inclusão e de redução da desigualdade, de fato uma constante em diversos países da região na esteira de fracassadas políticas neoliberais nas décadas precedentes ao fim do milênio (BOSCHI, 2011, p. 9).
\end{abstract}

Há, portanto, uma ênfase na questão do desenvolvimento. Tal temática está largamente relacionada à própria trajetória do continente latino-americano: a discussão sobre desenvolvimento na América Latina se reinstalou na agenda pública após a crise do paradigma neoliberal (BOSCHI E GAITÁN, 2013, p.1-3).

Desde a última década, os países latino-americanos vêm se caracterizando por um enfraquecimento do paradigma neoclássico, produzindo-se, em certa medida, determinado consenso acerca da necessidade de níveis maiores de regulação econômica. Nesse sentido, a crise financeira de 2008 parece ter potencializado essa necessidade. Entretanto, não há unanimidade em torno do discurso neodesenvolvimentista, uma vez que a elite se divide entre aqueles que ainda seguem os preceitos neoliberais e os que defendem uma plataforma mais semelhante à tradição desenvolvimentista (BOSCHI, 2011, p.7-26).

Da geração de um novo compromisso desenvolvimentista, surge a necessidade de analisar o papel do Estado, entendido como um propulsor da ruptura das complementaridades negativas, as quais derivam-se das trajetórias centradas no mercado. Nesse sentido, há três aspectos que são considerados: a natureza das instituições, a intervenção estatal e as trajetórias (BOSCHI, 2011, p.7-26). Verifica-se, portanto, uma aproximação do conceito de "path dependence" (dependência da trajetória), a qual - em sua versão mais ampla - refere-se à "relevância causal de estágios precedentes em uma sequência temporal" (PIERSON, 2000, p.252).

Existe a noção de que o desenvolvimento institucional está relacionado a path dependence, pois eventos como crises produz uma nova forma de "fazer as coisas" (SANDERS, 2006, p.39). Dessa forma, o entendimento do papel do Estado abarca uma dimensão histórica, visto que considera tanto o papel assumido na nova conjuntura na superação dos fatores de atraso econômico quanto o legado de cunho estatal desenvolvimentista (BOSCHI, 2011, p.7-26).

Nessa perspectiva, o neodesenvolvimentismo refere-se a um modelo ainda em construção que se baseia na interlocução entre Estado e setor privado. A dimensão social é 
colocada como fator de desenvolvimento, em que as políticas sociais possuem papel relevante na inclusão das camadas sociais e o Estado é visto como principal propulsor dessas políticas. São enfatizadas as dinâmicas endógenas, embora a globalização implique em limitações às periferias (BOSCHI, 2011, p.7-26).

As análises feitas por Schneider (2009) e Boschi (2011) podem aparentar distanciamento e até oposição. Porém, para fins desse artigo, ambas serão consideradas no estudo de caso. O argumento aqui é que o Brasil apresenta uma mistura dos fatores apresentados em ambas as análises. A economia política se classificaria, assim, em duas dimensões: a hierárquica e a desenvolvimentista. Dessa forma, o Brasil possui elementos de uma Economia de Mercado Hierárquica, mas não se pode esquecer o papel que o Estado possui em relação às polícias sociais na contemporaneidade.

Nesse contexto, o tema da desigualdade social é bastante relevante na compreensão de como essas dimensões se relacionam entre si. O Programa Minha Casa Minha Vida (PMCMV) é um programa do governo federal, cujo objetivo é promover a construção de moradias ${ }^{4}$.

Como forma de analisar as duas dimensões citadas, serão verificados os seguintes elementos do Programa: o envolvimento do setor privado e a divisão entre beneficiários. Ademais, pretende-se analisar a relação entre o programa e as demandas trazidas pela crise de 2008. Para tal, será necessário fazer um mapeamento dos agentes envolvidos no Programa (stakeholders), tanto por parte de sua implementação quanto pelos seus beneficiários. Suas regras de funcionamento também serão consideradas, destacando as relações dentro das cinco esferas delineadas por Hall e Soskice (2001).

Com isso, espera-se identificar elementos das dimensões hierárquica e desenvolvimentista de modo a esclarecê-las e contribuir para o debate sobre uma possível variedade de capitalismo presente no Brasil.

\section{ESTUdO DE CASO: O PROGRAMA MINHA CASA MINHA VIDA E A CRISE DE 2008}

O Programa Minha Casa Minha Vida (PMCMV) foi criado em 2009 pela Medida Provisória $n^{\circ} 459$ durante o segundo mandato do governo de Luiz Inácio Lula da Silva (2003-2011). Em 2003, com a criação do Ministério das Cidades, a política nacional de habitação é reestruturada e os recursos orçamentários para subsidiar financiamentos

4Ver em: <http://www.caixa.gov.br/habitacao/mcmv/> Último acesso: 30/11/2013. 
habitacionais são ampliados. Dilma Rousseff, ao assumir a Presidência da República em 2011, mantém o programa na agenda prioritária do governo.

Entre os principais objetivos do programa estão a redução significativa do déficit habitacional no Brasil, com a construção de moradias populares destinadas principalmente à população de baixa renda; a regularização fundiária e urbana; e o aumento dos investimentos no setor da construção civil. Além disso, o PMCMV tem por intenção a criação de uma fonte de demanda de capital e trabalho, uma vez que o programa foi adotado como uma medida anticíclica à crise mundial econômica de 2008. Dutra (2010, p.91) afirma que essa demanda responde à questão por que o programa destina os financiamentos apenas para as construtoras, em detrimento de outras formas não-lucrativas de organização de trabalho, como por exemplo, as cooperativas.

O PMCMV é dividido em duas fases. De acordo com o Ministério das Cidades a primeira fase (MCMV 1) se propôs a contratar um milhão de moradias destinadas a famílias de baixa renda (de até 10 salários mínimos). Os recursos do programa foram divididos por regiões do país tomando por parâmetro o déficit habitacional de cada região, como mostra a tabela a seguir:

Tabela 02: Investimentos do PMCMV por região do Brasil

\begin{tabular}{c|c}
\hline Região & Investimento do MCMV(\%) \\
\hline Sudeste & 37 \\
\hline Nordeste & 34 \\
\hline Sul & 12 \\
\hline Norte & 10 \\
\hline Centro-Oeste & 7 \\
\hline
\end{tabular}

Fonte: Ministério das Cidades $(2012,9)$

Nota-se que o déficit habitacional está concentrado na região Sudeste, sendo São Paulo o Estado com o maior índice, 55\%. O estudo realizado pelo Ministério das Cidades (2012, p.11) demonstra que o perfil da demanda do programa é aquele que corresponde a famílias com renda de até três salários mínimos, pois do total do déficit habitacional brasileiro, essas famílias representam $72 \%$ do índice. O déficit habitacional brasileiro pode ser caracterizado ainda por três componentes. O primeiro deles diz respeito à coabitação, que são famílias que dividem um mesmo domicílio. Já o segundo está relacionado ao ônus excessivo com aluguel de famílias que gastam até 30\% ou mais com o pagamento de aluguel. O terceiro e último componente, compreende a habitação precária, ou seja, 
moradias improvisadas, correspondendo a 23\% de domićlios no Brasil. (MINISTÉRIO DAS CIDADES 2012, p.11-12)

Vale ressaltar que do déficit habitacional total, $83 \%$ estão na zona urbana e $17 \%$ na zona rural. Segundo a Secretaria Nacional de Habitação do Ministério das Cidades o déficit concentrado na zona urbana deve-se aos componentes de coabitação e de ônus excessivo com aluguel. Já na zona rural o déficit é caracterizado pela habitação precária, caracterizada principalmente pela falta de infraestrutura básica, água, luz e saneamento básico, características estas muito presentes também no meio urbano.

$\mathrm{Na}$ segunda fase do programa (MCMV 2) houve o ajuste dos valores das faixas de renda, que atualmente opera com as seguintes Faixas:

Tabela 03: Faixas de Renda do PMCMV.

\begin{tabular}{c|c}
\hline Faixa & Renda \\
\hline 1 & Até $\mathrm{R} \$ 1.600,00$ \\
\hline 2 & Até $\mathrm{R} \$ 3.100,00$ \\
\hline 3 & Entre $\mathrm{R} \$ 3.100,00$ e $\mathrm{R} \$ 5.000,00$ \\
\hline
\end{tabular}

Fonte: Ministério das Cidades $(2012,10)$.

De acordo com a Caixa Econômica Federal, a faixa 1 possui a maior parcela de subsídio, chegando a cobrir 95\%. A faixa 2 tem um subsídio parcial, já a faixa 3 não possui subsídio, as prestações são de acordo com a renda do mutuário e cobertura do novo fundo garantidor.

Até o ano de 2012, o PMCMV contratou 1.728.55 unidades habitacionais que se concentraram nos estados de São Paulo, Minas Gerais, Bahia, Rio Grande do Sul, Paraná, Rio de Janeiro e Goiás, respectivamente. Os impactos esperados pelo PMCMV estão centrados principalmente na atividade econômica brasileira. O Ministério das Cidades destaca que a estimativa é de que o programa gere uma média anual de 864 mil empregos diretos e indiretos. O PMCMV tem sido responsável por gerar novos negócios nos mercados de materiais e serviços voltados ao setor da construção civil.

Ainda destacando a sua estrutura, o programa possui algumas vertentes operacionais que visam atender de maneira diferenciada cada padrão de renda familiar ${ }^{5}$, sendo eles:

$\checkmark$ Programa Nacional de Habitação Urbana (PNHU): Tem por objetivo promover a produção ou aquisição de novas unidades habitacionais ou a

\footnotetext{
${ }^{5}$ Fonte: $<$ http://www.cidades.gov.br/index.php/minha-casa-minha-vida $>$ Último acesso em: 24/07/2013.
} 
requalificação de imóveis urbanos, para famílias com renda mensal de até $\mathrm{R} \$$ $5.000,00$.

$\checkmark$ Financiamento com recursos do Fundo de Garantia do Tempo de ServiçoFGTS: Atendimento a famílias com renda mensal de até $\mathrm{R} \$ 5.000,00$.

$\checkmark$ Fundo de Arrendamento Residencial - FAR: Atendimento as famílias com renda mensal de até $\mathrm{R} \$ 1.500,00$ na área de atuação.

$\checkmark$ Fundo de Desenvolvimento Social - FDS: Atendimento a famílias com renda mensal de até $\mathrm{R} \$ 1.600,00$, organizadas em cooperativas habitacionais ou mistas, associações e demais entidades provadas sem fins lucrativos visando a produção, aquisição e requalificação de imóveis urbanos.

$\checkmark$ Oferta pública de recursos: Atendimento a famílias com renda mensal de até R\$ 1.600,00 em Municípios com população de até 50.000 habitantes.

$\checkmark$ Programa Nacional de Habitação Rural (PNHR): Tem por objetivo subsidiar a produção ou reforma de imóveis aos agricultores familiares e trabalhadores rurais cuja renda familiar anual bruta não ultrapasse $\mathrm{R} \$ 60.000,00$.

Cabe aqui levantar algumas questões que se fazem pertinentes para o conhecimento da dinâmica do programa. A principal delas, como já destacada anteriormente, se refere a como a crise financeira de 2008 influenciou o andamento do programa. Além disso, é importante destacar quais os principais desafios que o governo enfrenta em sua implementação e quais foram as principais modificações que o PMCMV sofreu depois de sua criação. Para alcançarmos algumas dessas repostas, foi realizada entrevista com um dos gestores do Departamento de Habitação do Ministério das Cidades.

Ao ser questionado sobre o que o programa trouxe de inovação na política habitacional em comparação com programas anteriores, o gestor contextualiza que embora o fundamento econômico do capitalismo financeiro não tenha sido alterado de forma significativa durante o governo Lula, houve maior investimento às políticas distributivas e compensatórias de forma incisiva como, por exemplo, o Programa Bolsa Família, o Programa Nacional de Fortalecimento da Agricultura Familiar - PRONAF, Luz para Todos e o próprio Minha Casa Minha Vida. Em 2008, houve a necessidade do governo de aprofundar mais essa política. O que favorece a política do MCMV, segundo o gestor, é o alto grau de subsídio para as faixas de renda menores, chegando até $95 \%$. Ele analisa que o elevado grau de transferência tem causado impactos significativos na máquina pública, necessitando, portanto, ser revisada. 
Essa política tem sido considerada avançada, pois além de alcançar cerca de 3 milhões de moradias, que corresponde à metade do déficit habitacional, contrapõe-se à exclusão social historicamente presente no Brasil. O Programa se sustentou de forma eficaz durante a crise econômica internacional mesmo com baixo crescimento do PIB.

As principais estratégias do governo Lula estavam voltadas em distribuir subsídios de forma mais igualitária e realista com a capacidade do Estado. O PMCMV reproduz parte da antiga política do Banco Nacional de Habitação (BNH), que desempenhou o mesmo papel que o programa desempenha atualmente, durante a ditadura militar, de ativar a economia sustentando as encomendas do grande setor da Construção Civil que era responsável na época, como hoje, pelo pleno emprego. Desse modo, não houve uma alteração significativa em relação a programas já implementados.

Em relação às principais modificações que o programa sofreu desde a sua criação, o gestor entrevistado aponta que do MCMV 1 para o MCMV 2 houve melhorias, como a especificação de cuidados com a inserção nas cidades e nos conjuntos. A Presidência da República tem concentrado programas para dotar as áreas de equipamentos, com uma infraestrutura básica para a população como unidades de saúde, escolas, saneamento básico, energia, no entanto, esse esforço é principalmente de iniciativa do poder municipal.

Os resultados dessas alterações ainda não são significativos ao longo da implantação do processo, principalmente por se tratar de uma política centralizada. Além disso, antes o programa possuía um único agente financiador, a Caixa Econômica Federal, enquanto agora, além da Caixa, o Banco do Brasil participa como agente. Um dos motivos para a entrada da instituição financeira deve-se à dinamização do financiamento, bem como reclamações do excesso de burocracia exercida pela Caixa Econômica.

Os principais desafios que o governo enfrenta na implementação do programa referem-se à interação com os municípios que possuem uma política própria e, como afirma o gestor, são facilmente capturados por essa dinâmica do grande capital. Além disso, há dificuldade também em estados com nível de acesso mais difíceis, como por exemplo, algumas regiões do Norte do país. A ação da política vinda de baixo pra cima é o que tem mitigado os impactos maiores desses investimentos.

O gestor afirma que há a necessidade de que outros atores se tornem protagonistas, como entidades de movimentos sociais e produção de cooperativas que precisariam de um apoio técnico ao próprio programa, como o MCMV Entidades. Na faixa 1, as grandes construtoras pretendem maximizar o lucro e fazem isso nas faixas 2 e 3 também. Ademais, 
cabe destacar a baixa capacidade de gestão do Estado, que demora em licenciar e aprovar os projetos, o que causa certa morosidade ao programa.

Para o gestor entrevistado, os principais beneficiados com o programa pertencem à população de baixa renda. Mas destaca que há muitos interesses envolvidos, como o grande capital da construção civil e as grandes construtoras que possuem uma parcela significativa do programa , a fim de maximizar o seu lucro.

Quando indagado sobre as ações do programa para os indivíduos que se encontram em risco social, afirma que há demandas dessa natureza, desde o Rural até o FAR, que possuem uma flexibilidade maior de renda, representando pessoas assentadas, em situações de calamidade, além de incentivos em cidades do interior onde o custo é menor do que na capital. Essas ações têm surtido efeito, mas apresentam algumas dificuldades, como nos casos em que o custo da terra é muito alto e consequentemente o custo da construção.

Em relação a esse quadro, a Portaria nº 610/2011 do Ministério das Cidades, descreve os critérios de seleção de candidatos para a adesão do programa. Entre eles destacam-se: famílias residentes em áreas de risco ou insalubres ou que tenham sido desabrigadas; famílias com mulheres responsáveis pela unidade familiar; e famílias de que façam parte pessoas com deficiência.

Há ainda preferência para aqueles que se encontram em situação de rua e que recebem acompanhamento sócio assistencial do Distrito Federal, estados e municípios, bem como instituições privadas sem fins lucrativos, que trabalhem em parceria com o poder público.

Questionado sobre as vantagens e desvantagens do programa, o gestor destaca que a principal vantagem é o de acionar a economia tendo um cunho estratégico, permitindo aquisição de moradia de forma mais barata e rápida. Quanto à desvantagem, destacou a forma centralizada de formulação da política e de revisão desta, o que impede que se corrijam distorções presentes na implementação. O gestor afirma que é preciso ampliar o espaço da produção não-capitalista no processo, principalmente na operação da Faixa 1.

\subsection{O MCMV, o setor da Construção Civil e a Crise de 2008}

Como já foi destacado, o programa surgiu como principal resposta, de investimento e inclusão, ao contexto da crise, desde o Bolsa Família. O impacto da crise no Brasil, segundo o gestor, não foi significativo, pois a dependência em relação ao comércio exterior é pequena e muito segmentada - os bens com valor agregado que o país exporta tem 
impacto muito limitado na economia. A crise repercutiu na retração de investimentos, uma vez que a política tem uma dinâmica própria que sustenta hoje o desenvolvimento da economia brasileira.

Mesmo com a atual conjuntura de crise econômica, o país tem alcançado o que se chama de "pleno emprego". Um dos principais impactos gerados pelo PMCMV foi no setor da construção civil. Analisando a evolução do PIB do setor desde o primeiro trimestre de 2003, início do mandato do governo Lula, observa-se crescimento constante, com pequenas oscilações. A exceção está no terceiro trimestre de 2008, período em que a crise norte-americana se evidencia afetando os mercados mundiais em diferentes níveis e graus. Ainda assim, não houve uma quebra de tendência de alta neste indicador, destaca Dutra (2008), o qual afirma ainda que ocorreu apenas uma oscilação com as anteriores, em um grau um pouco mais elevado, sendo contornado rapidamente com a expectativa de recuperação da economia mundial por parte de alguns agentes econômicos.

O objetivo estratégico do programa era o de impulsionar a economia mitigando os riscos de impacto da crise econômica global sobre o setor, bem como na oferta de crédito imobiliário. De acordo com o Departamento de Habitação do Ministério das Cidades, 30 grandes construtoras no Brasil detêm 50\% do programa, sendo que algumas empresas chegam a concentrar cerca de 60.000 contratos. O gestor entrevistado afirma que essas grandes construtoras se concentram nas faixas 2 e 3 , mas possuem parcela significativa de contratos na faixa 1. Apesar do interesse relativo, essas empresas buscam isenção e não se interessam por rendas maiores. As grandes construtoras constroem rapidamente, pois já trabalham com pré-moldados que possuem grande agilidade.

Em relação a atraso de cronogramas, o programa não apresenta tantos problemas, justamente por essa agilidade de construção citada. O maior motivo de atraso é o descontrole econômico do processo, como por exemplo, episódios de falência.

O Programa de Aceleração do Crescimento - PAC contribuiu de forma significativa para o crescimento da construção civil como um todo, uma vez que o programa busca investir incisivamente em obras de infraestrutura para todo o país, como transporte, energia, recursos hídricos e saneamento. De acordo com estudo realizado pela Associação Brasileira da Indústria de Materiais de Construção - ABRAMAT, a projeção do impacto anual dos investimentos em construção do programa MCMV programa integrante do PAC, no período de 2011-2014 será de:

Tabela de projeção anual de investimentos em construção do MCMV (2011-2014). 


\begin{tabular}{c|c}
\hline Empregos em toda a economia & $\mathbf{1 . 4 3 4 . 7 9 1}$ \\
\hline Na construção & 984.342 \\
\hline Em outros setores & 450.449 \\
\hline Renda em toda a economia (R\$ milhões & $\mathbf{6 2 . 8 5 6 , 8 1}$ \\
\hline Na construção & $37.552,22$ \\
\hline Em outros setores & $25.304,59$ \\
\hline
\end{tabular}

Fonte: ABRAMAT, $(2010,4)$

Observa-se que a construção civil é um importante setor para a movimentação econômica do Brasil, entretanto, mesmo com forte ritmo de crescimento, um dos maiores gargalos existentes no setor é a falta de mão de obra qualificada, além de condições de trabalho insalubres, com forte risco de acidentes e mortes.

$\mathrm{O}$ viés macroeconômico dominante que o MCMV, criado como uma política de habitação urbana, se mostra ainda ineficiente neste aspecto pela questão habitacional e de inserção urbana em si. Primeiro, porque a dinâmica do programa é intensamente atrelada ao grande capital do setor, então a iniciativa dos subprogramas principais, como o Minha Casa Construtora, que é 90\% do programa, depende da iniciativa da construtora. Há ainda uma dependência de sintonia fina com as prefeituras municipais que coordenam diretamente a questão do terreno, que às vezes é localizado em lugares sem o mínimo de infraestrutura básica necessária. Com a finalidade de aprimorar o programa, o governo federal lançou recentemente o "Minha Casa Melhor" que concede crédito de até R\$ 5.000,00 para as famílias beneficiadas para a compra de móveis e eletrodomésticos.

\section{CONCLUSÃO}

Como mencionado na primeira sessão deste artigo, a economia política na abordagem de VoC é vista como um terreno em que diversos atores buscam avançar em seus interesses de forma racional e estratégica com outros atores. No que se refere ao processo de políticas públicas (policy-making), como destaca Hall e Soskice (2001), a questão central que se coloca é a cooperação entre os agentes, uma vez que se faz necessário que os atores cooperem uns com os outros de forma mais eficiente.

Observamos essa relação quando analisamos a forma como o Programa Minha Casa Minha Vida é inserido no Brasil em meio a uma conjuntura de crise econômica como estratégia anticíclica à crise. Fica evidente que o setor da construção civil (suas grandes empresas) atua como ator central dessa relação juntamente com o Estado, que por sua vez 
gera uma política distributiva, mantém a economia ativa e aumenta o índice de emprego neste setor.

Conclui-se também, com a abordagem realizada neste trabalho, que o crescimento do setor da construção civil está diretamente ligado ao aumento da demanda por novos imóveis residenciais, o que por sua vez, incentiva a atividade das construtoras, que recorrem a recursos bancários na intenção de expandir as suas operações. A falta de interesse por parte de construtoras, como mencionado em nossa análise, na construção de moradias populares vem beneficiando, afirma Dutra (2010, p.98), a emergente classe média brasileira, chamada Classe $\mathrm{C}$, a qual possui disponibilidades maiores de renda que permitem que esta financie imóveis com preços atrativos às construtoras. Logo, a oferta imobiliária para este segmento é maior, o que acaba por baratear o preço final dos imóveis e a aumentar a demanda por estes, e ainda:

(...) o benefício à classe média é recorrente: aconteceu também com o extinto
BNH. Aliás, a bancarização da habitação no Brasil foi e é entrave para uma
maior efetividade dos programas habitacionais no país. Projetos habitacionais
verdadeiramente públicos e populares, com $100 \%$ de fundos para construção
partindo da União, ainda são escassos, o que acaba por reduzir a efetividade
do PMCMV no combate ao déficit habitacional brasileiro. (DUTRA, 2010,
p.98)

Nota-se também a noção de Hierarquia demonstrada por Schneider (2009) no que se refere ao processo de tomada de decisão. Diferentemente da EML em que as decisões são tomadas baseadas no mercado e na EMC em que são altamente negociadas, na Economia de Mercado Hierárquica as decisões são tomadas de forma unilateral e centralizada, sendo que em algumas dimensões há uma regulação de cima para baixo, o que se evidencia na implementação do PMCMV, destacando-se as duas dimensões da classificação da economia política referidas, respectivamente, por Schneider (2009) e Boschi (2011), ou seja, hierárquica e desenvolvimentista.

A dimensão hierárquica está refletida na centralidade com a qual as decisões são tomadas, principalmente aquelas tomadas no âmbito do Estado. O fato de a formulação do Programa ter se concentrado no núcleo duro da Presidência da República, por exemplo, é uma demonstração dessa centralidade. Por outro lado, há simultaneamente uma preocupação com o desenvolvimento social, expressa na tentativa de inclusão das camadas populares de renda baixa. Enquanto esses elementos de cunho hierárquico e desenvolvimentista podem ser complementares em algumas situações, eles também podem ser contrapostos em alguns casos - como mostram as próprias dificuldades que o PMCMV encontra na inserção de grupos mais desfavorecidos. 
A formulação e a eficácia do PMCMV se devem, portanto, aos incentivos gerados que foram complementares às capacidades inseridas na economia política existente no Brasil, a qual está relacionada diretamente a ambos os aspectos hierárquicos e desenvolvimentistas presentes nas instituições brasileiras.

\section{REFERÊNCIAS BIBLIOGRÁFICAS:}

ABRAMAT. 2010. Projęão dos Impactos dos Investimentos do PAC 2 e do Programa Minha Casa Minha Vida 2.

BOSCHI, R. 2011. Instituições, trajetória e desenvolvimento: Uma discussão a partir da América Latina. Em: BOSCHI, R. (org). Variedades de Capitalismo, Politica e Desenvolvimento na América Latina. Belo Horizonte: Editora UFMG.

BOSCHI, R.; GAITÁN, F. 2013. Strategic Elites and Institutional Change: the emergence of postneoliberalism in Brazil and Argentina. Paper apresentado na $1^{\text {a }}$ Conferência Internacional sobre Políticas Públicas.

DUTRA, L. G. B. 2010. A atuação do Governo Lula no combate ao Déficit Habitacional Brasileiro: O Caso do Programa Minha Casa Minha Vida. Universidade Federal de Santa Catarina (UFSC). Monografia.

FLEURY, S. 2006. Democracia, descentralização e desenvolvimento. Em: FLEURY, S. (org.) Democracia, descentralização e desenvolvimento: Brasil e Espanha. Rio de Janeiro: FGV Editora.

HALL, P.; SOSKICE, D. 2001. Varieties of Capitalism: The Institutional Foundations of Comparative Advantage. Oxford: Oxford University Press.

HALL, P.; GINGERICH, D. W. 2009. Varieties of capitalism and institutional complementarities in the political economy. BritishJournalofPolitical Science, 39 (3): p. 449-482. Disponível em: < http://dash.harvard.edu/bitstream/handle/1/4481421/Hall VarietiesCapitalismEmpiric al.pdf?sequence $=2>$ Último acesso: 01 de dezembro de 2013.

MARCH, J. G. (with the assistance of Chip Heath). 1994. A Primer on Decision Making: how decisions happen. Nova York: The Free Press.

MINISTÉRIO DAS CIDADES. 2012. Novo Patamar da Habitação Social Brasileira. ANEXO DA PORTARIA Nº 610, DE 26 DE DEZEMBRO DE 2011 fl. 02

NORTH, D. 1991. Institutions. The Journal of Economic Perspectives, Vol 5, No 1, pp. 97-112. 
PIERSON, P. 2000. Increasing Returns, Path Dependence, and the Study of Politics. The American Political Science Review, Vol. 94, No. 2, pp. 251-267

SANDERS, E. 2006. Historical Institutionalism. Em: ROCKMAN, B.; RHODES, R.A.W.; BINDER, S., The Oxford Handbook of Political Institutions. Oxford: Oxford University Press.

SCHNEIDER, B. R. 2009. Hierarchical Markets Economies and Varieties of Capitalism in Latin America. OCSID Working Paper.

STREECK, W.; THELEN, K. 2005. Beyond Continuity: Institutional Change and Advanced Political Economies. Oxford: Oxford University Press. 